\title{
Incorporation of water sludge, silica fume, and rice husk ash in brick making
}

\author{
Badr El-Din Ezzat Hegazy, Hanan Ahmed Fouad and \\ Ahmed Mohammed Hassanain* \\ Department of Civil Engineering, Faculty of Engineering at Shoubra, Benha University, Cairo, Egypt
}

(Received April 2, 2012, Revised April 20, 2012, Accepted April 24, 2012)

\begin{abstract}
The water sludge is generated from the treatment of water with alum. Disposing of sludge again to the streams raises the concentrations of aluminum oxides in water, which has been linked to Alzheimer's disease. The use of water treatment plant (WTP) sludge in manufacturing of constructional elements achieves both the economical and environmental benefits. Due to the similar mineralogical composition of clay and WTP sludge, this study investigated the complete substitution of brick clay by sludge incorporated with some of the agricultural and industrial wastes, such as rice husk ash (RHA) and silica fume (SF). Three different series of sludge to SF to RHA proportions by weight were tried, which were (25: 50: 25\%), (50:25: 25\%), and (25: 25: 50\%), respectively. Each brick series was fired at 900, 1000,1100 , and $1200^{\circ} \mathrm{C}$. The physical and mechanical properties of the produced bricks were then determined and evaluated according to Egyptian Standard Specifications (E.S.S.) and compared to control clay-brick. From the obtained results, it was concluded that by operating at the temperature commonly practiced in the brick kiln, a mixture consists of $50 \%$ of sludge, $25 \%$ of SF, and $25 \%$ of RHA was the optimum materials proportions to produce brick from water sludge incorporated with SF and RHA. The produced bricks properties were obviously superior to the $100 \%$ clay control-brick and to those available in the Egyptian market.
\end{abstract}

Keywords: water treatment sludge; sludge disposal; clay; brick; silica fume; rice husk ash

\section{Introduction}

The disposal of the residuals generated during the various water treatment processes must receive careful consideration. These residuals include wash water and sludge. The sludge is composed of the impurities removed and precipitated from the raw water together with the residuals of any treatment chemical used. Disposal of alum sludge can be a major concern for water treatment plants (WTPs). Most of the WTPs in Egypt discharge the sludge into the river Nile again with no treatment at all. The discharging of sludge into water body leads to accumulative rise of aluminum concentrations in water, aquatic organisms, and human bodies. Some researchers have linked aluminum's contributory influence to occurrence of Alzheimer's disease, children mental retardation, and the common effects of heavy metals accumulation (Prakhar and Arup 1998). Consequently stringent standards of

*Corresponding author, Professor, E-mail: eng_ahmed_hassanain@yahoo.com 
effluent discharge are coming into effect, and thus proper management of the sludge becomes inevitable.

The use of water treatment sludge in various industrial and commercial manufacturing processes has been reported in UK, USA, Taiwan and other parts of the world. Successful pilot and full-scale trials have been undertaken in brick, cement, artificial aggregate and ceramic making as well as commercial land application (Godbold et al. 2003, Huang et al. 2005, Toya et al. 2007). The utilization of water treatment residual (WTR) was proposed, in a study carried out in USA, as a cost-effective technology for arsenic soil remediation (Nagar 2008). The ultimate goal of that study was to evaluate the effectiveness of WTR (Al- and Fe-based) in lowering the human health risk from soil arsenic exposure. The mineralogical composition of the "water treatment sludge" is particularly close to that of clay (Lai and Liu 2004). This fact encourages the use of water treatment sludge in brick manufacture.

Several trials have been reported in this purpose. In a study that was conducted in the Netherlands, the researchers have manufactured bricks from clay to which water sludge was added (Feenstra et al. 1997). The bricks were assessed in terms of production technique (firing temperature) and environmental impact (leaching behavior). The results of the study were then taken as a basis for closer evaluation of the feasibility of this option. As a result, the process has now become reality. Another research carried out in the UK, assessed the potential of incorporating aluminum and ferric coagulant sludge in various manufacturing processes including clay brick making (Godbold et al. 2003). A mixture consists of about 10\% of the water treatment sludge and sewage-sludge incinerated-ash was added to about $90 \%$ of natural clay to produce the brick. A new study was conducted in Taiwan (Lin et al. 2006). In this study, an effort was endeavored to investigate the properties of water permeable bricks made of water treatment sludge and bottom ash. It was concluded that a $20 \%$ weight content of bottom ash added to $80 \%$ weight content of water treatment sludge under a sintering condition of $1150^{\circ} \mathrm{C}$ for 360 minutes can generate brick complying with the Chinese standard specifications for first degree brick. Also in Taiwan, a study had been made to use a mixture of WTP sludge and dam sediment as raw materials for brick making through the sintering process (Huang et al. 2001). A satisfactory result was achieved when the ratio of the WTP sludge was less than $20 \%$ of the mixture. In Egypt, similar studies investigated the use of sludge as a complete or partial substitute for clay in brick manufacturing (Hegazy 2007, Hassanain 2008, Ramadan et al. 2008). In this trend, different series of sludge and clay proportioning ratios were tried, which involved the addition of sludge with ratios between 50 and $100 \%$ by weight. Each series was fired at different temperatures between 950 and $1100^{\circ} \mathrm{C}$. The physical properties of the produced brick were then determined and evaluated according to E.S.S. From the obtained results, it was concluded that $50 \%$ was the optimum sludge addition to produce brick from sludge-clay mixture.

Silica fume (SF) is a by-product of producing silicon metal or ferrosilicon alloys in smelters using electric arc furnaces. While these are very valuable materials, the by-product SF is of more importance to the concrete industry (Holland 2005). It falls into the general category of nuisance dust. Because of the name "silica fume" there are frequently questions raised regarding health issues of using this material in concrete. The general concern is with silicosis, which has been widely publicized within the construction industry. Because SF is amorphous and not crystalline, silicosis is not an issue. High dust concentrations may cause irritation to mucous membranes. Successful studies have been carried out on using SF in concrete making (Holland 2005, Kadri and Duval 2009). Also, in an Indian study, active silica from SF was progressively incorporated in a whiteware 
composition in substitution of quartz (Prasad et al. 2003). This study indicated the possibility of using SF in brick manufacture due to its high content of amorphous silica.

Agricultural wastes should, also, be handled and disposed of in an environmentally sound manner. The annual world production of rice crop is about 500 million tons, which represent $21 \%$ of the human food (Belonio 2005). Several trials have been made to use rice husks and rice husk ash (RHA) as a low cost concrete admixture because of its role as filler and pozzolan, in phenol adsorption from aqueous solution, in producing charcoal and supplementary cementitious materials, and in some other industrial uses such as brick making (Jauberthie et al. 2000, Crisp and Chowdhury 2001, Mahvi et al. 2004). In Nigeria, bricks were made from clay-sand mixes with different percentages of RHA and burnt in a furnace for different firing times (Rahman 1987). The firing durations at $1000^{\circ} \mathrm{C}$ were 2 hours, 4 hours and 6 hours. Test results indicated that lightweight bricks could be manufactured with RHA without any deterioration in the quality of bricks. In another study, the effects of RHA on the various properties of lateritic soil-clay mixed bricks were studied (Rahman 1988). The compressive strength of lateritic soil-clay mixed bricks increased almost linearly with increase in the percentage content of RHA. The latest approach study also, has been made in Taiwan (Chiang et al. 2009). Novel lightweight bricks have been produced by sintering mixes of dried water treatment sludge and rice husk. Samples containing up to $20 \mathrm{wt} . \%$ rice husk have been fired using a heating schedule that allowed effective organic burn-out. Rice husk addition increased the porosity of sintered samples. From the previous researches, it is clearly obvious that water treatment sludge, SF, and RHA could be used in manufacturing of clay brick.

The present study was devoted to use mixtures of water treatment sludge, SF, and RHA to produce crystalline aluminosilicate brick. Different mixing ratios and various firing temperatures were tried. The obligatory values of compressive strength, water absorption, and efflorescence assigned by the Egyptian Standard Specifications E.S.S. 1524/1993 for load bearing bricks were aimed to be met. Control clay brick, which made under the circumstances of the study, was used in comparison with the research brick along with some of the commercial brick types available in the Egyptian market.

\section{Materials and methods}

\subsection{Characterization of WTP sludge}

The alum sludge used in the study was generated from the clariflocculators of the Giza Water Treatment Plant at Giza Governorate, Greater Cairo. The chemical composition of sludge was identified by using the X-ray fluorescence (XRF) spectrometer according to ASTM C114-00. The complete chemical composition of alum sludge is summarized in Table 1.

The major chemical compositions of the sludge were silicon, aluminum, and iron oxides, as shown in Table 1. Clearly, those are extremely similar to the major chemical compositions of the brick clay, but with higher alumina content. The alumina content of brick clay is usually about $13 \%$ as indicated in Table 2. The phase composition was identified by using the X-ray diffraction (XRD) diffractometer according to ASTM C114-00. The phase composition of alum sludge is shown in Fig. 1.

The XRD scans were recorded from $5-60^{\circ} 2 \theta$. The XRD pattern of the water treatment plant sludge, shown in Fig. 1, indicates the presence of two major crystalline phases, namely, quartz




Table 1 The results of XRF test for sludge

\begin{tabular}{cc}
\hline \hline Item & Percentage by weight (\%) \\
\hline $\mathrm{SiO}_{2}$ & 43.12 \\
$\mathrm{Fe}_{2} \mathrm{O}_{3}$ & 5.26 \\
$\mathrm{Al}_{2} \mathrm{O}_{3}$ & 15.97 \\
$\mathrm{CaO}$ & 5.56 \\
$\mathrm{MgO}$ & 0.85 \\
$\mathrm{SO}_{3}$ & 1.49 \\
$\mathrm{Na}_{2} \mathrm{O}$ & 0.52 \\
$\mathrm{~K}_{2} \mathrm{O}$ & 0.26 \\
$\mathrm{Cl}^{-}$ & 0.012 \\
$\mathrm{L.O.I}$ & 26.79 \\
\hline
\end{tabular}

contains, in its composition, minerals that are similar to those commonly occurring in brick clays.

The concentration of suspended solids in sludge was raised to not less than $20 \%$ by filtering the sludge through a specially designed sand filter. The details of that filter are shown in Fig. 2. The concentration of the suspended solids of the sludge reaches $20 \%$ after two days. The thickened sludge are then collected from the filter, distributed, spread and subjected to air drying and direct sunlight for at least 14 days on drying beds.

The dried sludge is pulverized using a pestle and mortar. The powder is then sieved through a series of sieves. The sieving process is done to separate the impurities and large particles $(>0.075 \mathrm{~mm})$ of sand that may be included within the sludge.

The last stage of sludge preparation process involves the removal of the organic content, which indicated by a relatively high value of loss on ignition (L.O.I) given in Table 1 . This was done by

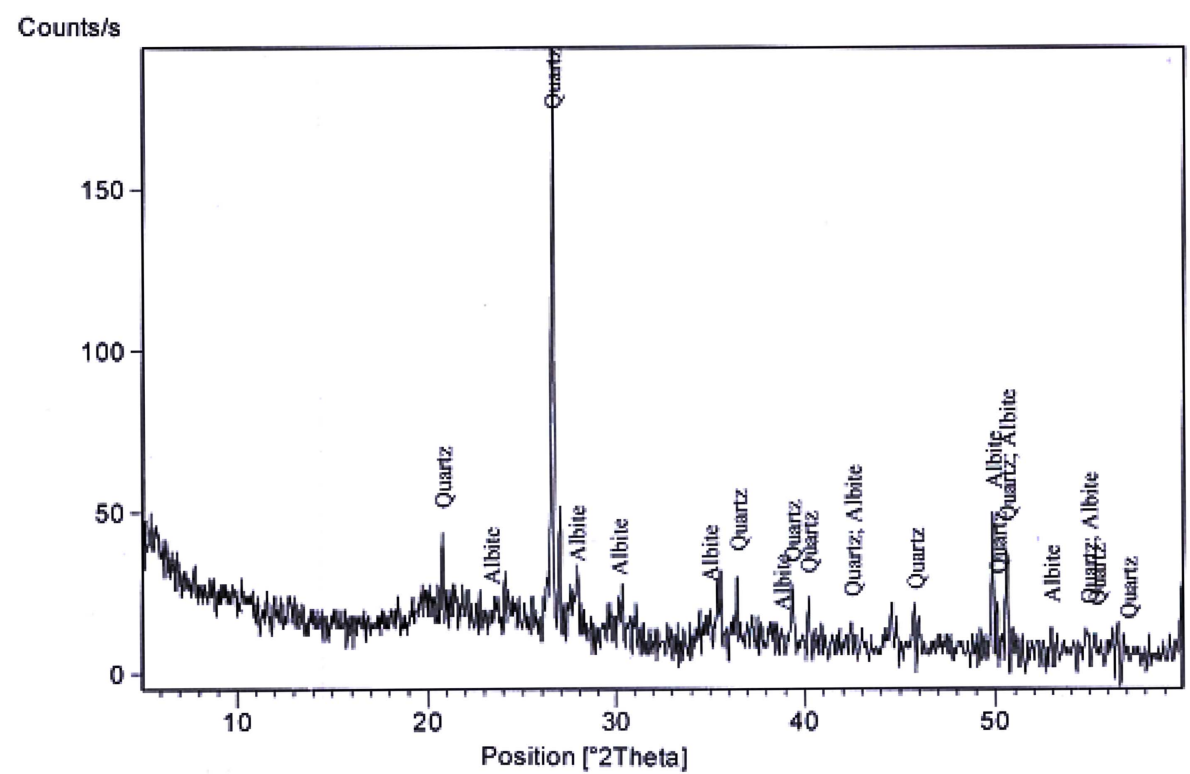

Fig. 1 XRD patterns for the WTP sludge 




Fig. 2 The sand filter used for concentrating the sludge

burning the sludge at moderate range of temperatures ranged from 150 to $350^{\circ} \mathrm{C}$ for 1 and 2 hours period. It was found that, burning the pulverized sludge dust at $350^{\circ} \mathrm{C}$ for 1 hour causes a loss in sludge weight equals $25 \%$. This removal ratio of organic content could be accepted.

\subsection{Characterization of clay}

The source of the clay used in this study was a local brick factory at Imbabah, Giza Governorate. The chemical composition of clay was identified by using the XRF spectrometer according to ASTM C114-00. The complete chemical composition of clay is summarized in Table 2.

From Table 2, it is clearly obvious that the major chemical compositions of the clay were silica, alumina, and ferric oxide, which are similar to that of the sludge. The strength of the brick depends largely on the percentage of silica in the raw materials. So, it was anticipated that the clay is more

Table 2 The results of XRF test for clay

\begin{tabular}{cc}
\hline \hline Item & Percentage by weight (\%) \\
\hline $\mathrm{SiO}_{2}$ & 65.32 \\
$\mathrm{Fe}_{2} \mathrm{O}_{3}$ & 7.51 \\
$\mathrm{Al}_{2} \mathrm{O}_{3}$ & 13.89 \\
$\mathrm{CaO}$ & 1.09 \\
$\mathrm{MgO}$ & 0.95 \\
$\mathrm{SO}_{3}$ & 0.05 \\
$\mathrm{Na}_{2} \mathrm{O}$ & 2.61 \\
$\mathrm{~K}_{2} \mathrm{O}$ & 0.75 \\
$\mathrm{TiO}_{2}$ & 1.46 \\
$\mathrm{P}_{2} \mathrm{O}_{5}$ & 0.28 \\
L.O.I & 5.87 \\
\hline
\end{tabular}




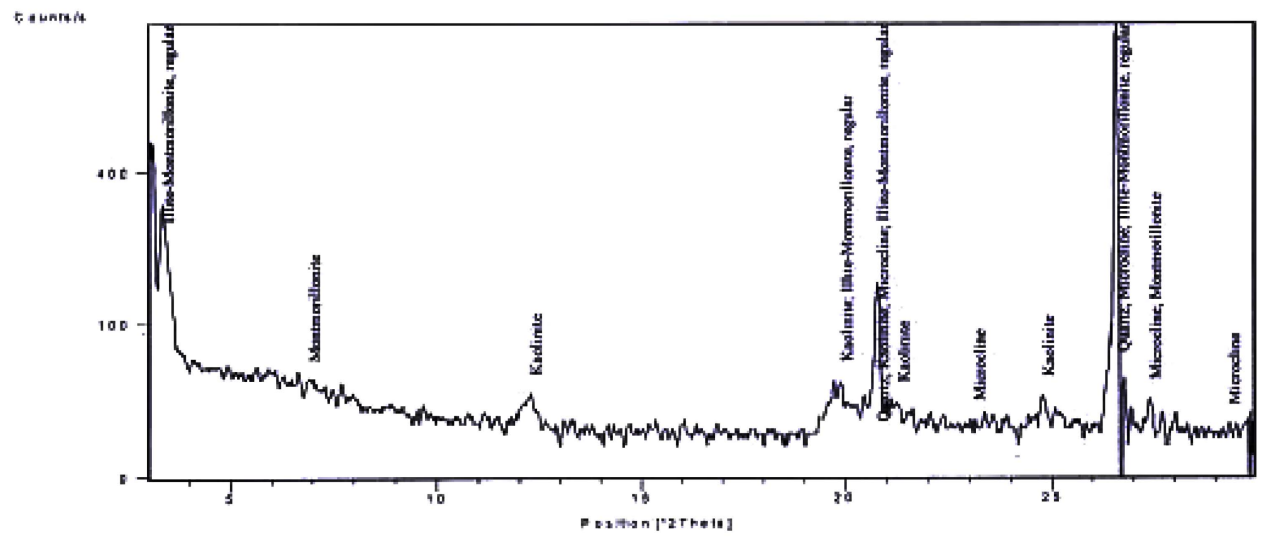

Fig. 3 XRD patterns for the clay

suitable for brick making than the sludge due to its obviously higher silica content. Also, the very low value of L.O.I. indicates low volatile and organic content, which suggested that the removal or reduction of the organic content in the clay before sintering was not required. The phase composition of clay was identified by using the XRD diffractometer, according to ASTM C114-00. The phase composition of clay is shown in Fig. 3.

The XRD scans were recorded from $0-30^{\circ} 2 \theta$. The XRD pattern of the powder clay, shown in Fig. 3, indicates the presence of five major crystalline phases, namely, kaolinite $\left[\mathrm{Al}_{2} \mathrm{Si}_{2} \mathrm{O}_{5}(\mathrm{OH})_{4}\right]$, montmorillonite $\left[\left(\mathrm{Na}_{\mathrm{X}}(\mathrm{Al}, \mathrm{Mg})_{2} \mathrm{Si}_{4} \mathrm{O}_{10}\left((\mathrm{OH})_{2}\right)_{\mathrm{Z}} \mathrm{H}_{2} \mathrm{O}\right)\right]$, quartz [ $\left.\mathrm{SiO}_{2}\right]$, microcline [ $\mathrm{K} \mathrm{Al} \mathrm{Si}_{3} \mathrm{O}_{8}$ ], and illite-montmorillonite, regular $\left[\mathrm{K}-\mathrm{Al}_{4}(\mathrm{Si} \mathrm{Al})_{8} \mathrm{O}_{20}\left((\mathrm{OH})_{4}\right)_{\mathrm{X}} \mathrm{H}_{2} \mathrm{O}\right]$. The clay is obtained in the form of large consolidated boulders, which require pulverizing and sieving before using in brick manufacturing, as in case of dried sludge. The clay is then oven dried to remove its moisture content.

\subsection{Characterization of SF}

The commercially available SF in the Egyptian market was used in this study. The chemical composition was identified by using the XRF spectrometer according to ASTM C114-00. The complete chemical composition of SF is summarized in Table 3. It is obvious that SF contains mainly silica, which is the major chemical composition of the brick clay and a small amount of alumina, as shown in Table 3. As mentioned previously, the strength of the brick depends largely on the percentage of silica in the raw materials. These facts indicate that SF could be an excellent substitute for brick clay. The phase composition of SF was identified by using the XRD diffractometer, according to ASTM C114-00. The phase composition of SF is shown in Fig. 4. The XRD scans were recorded from $5-60^{\circ} 2 \theta$. The XRD pattern of the SF, shown in Fig. 4, indicates that silica in the SF initially exists in the amorphous form, but will not remain porous and amorphous, when incinerated for a prolonged period at a temperature above $500^{\circ} \mathrm{C}$ (Holland 2005).

These results indicate that SF presents, in its composition, amorphous silica that is similar to that commonly occurring in brick clays. 
Table 3 The results of XRF test for SF

\begin{tabular}{cc}
\hline \hline Item & Percentage by weight (\%) \\
\hline $\mathrm{SiO}_{2}$ & 96.19 \\
$\mathrm{Fe}_{2} \mathrm{O}_{3}$ & 0.47 \\
$\mathrm{Al}_{2} \mathrm{O}_{3}$ & 1.41 \\
$\mathrm{CaO}$ & 0.01 \\
$\mathrm{MgO}$ & 0.75 \\
$\mathrm{SO}_{3}$ & 0.02 \\
$\mathrm{Na}_{2} \mathrm{O}$ & 0.31 \\
$\mathrm{TiO}_{2}$ & 0.01 \\
L.O.I & 0.81 \\
\hline
\end{tabular}

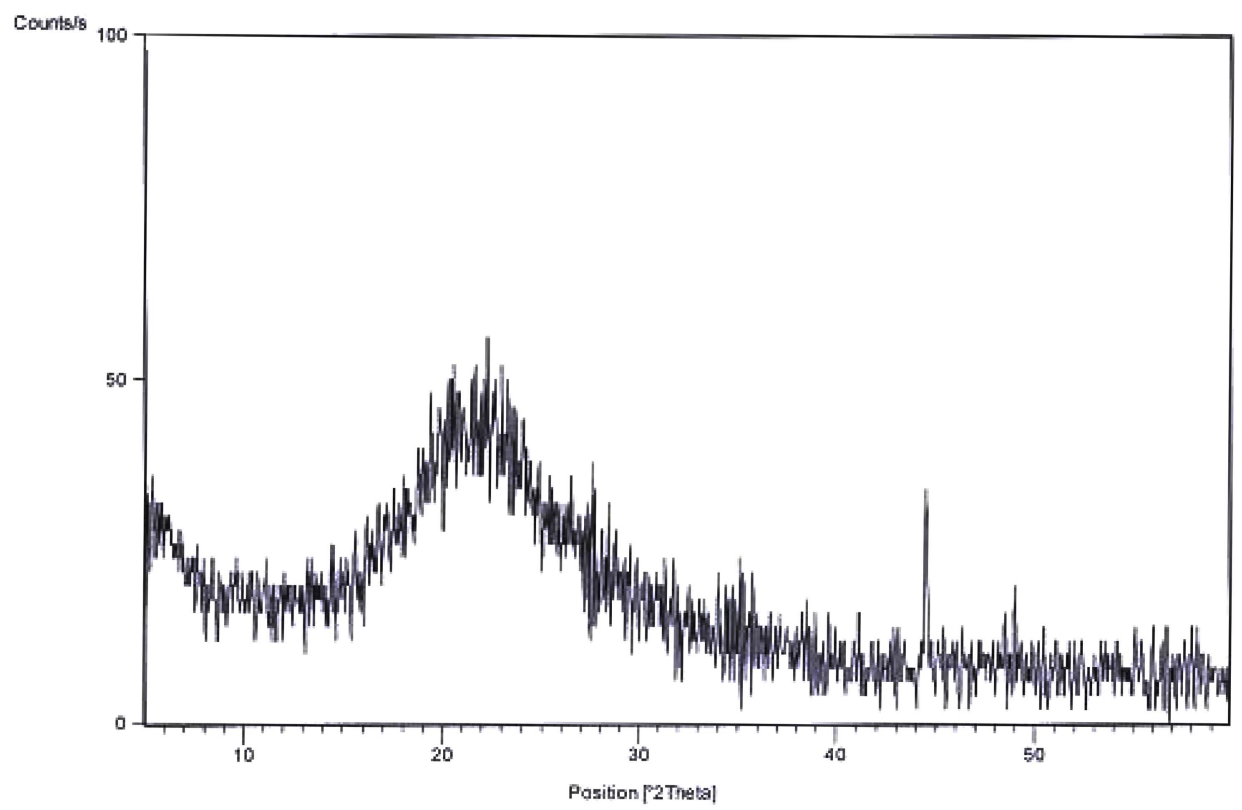

Fig. 4 XRD patterns for the SF

\subsection{Characterization of RHA}

The chosen source for rice husks used in this study was a local rice thresher at El-Qanater, Kalyobya Governorate. The rice husks require incineration, pulverizing and sieving to produce RHA to use it in brick manufacturing, as amorphous silica. It has been reported that at low temperatures $\left(600-700^{\circ} \mathrm{C}\right)$ silica in RHA is amorphous, and crystallization occurs when temperature goes above $700^{\circ} \mathrm{C}$ (Farooque et al. 2009). In this Study, rice husks were incinerated at $600^{\circ} \mathrm{C}$ for 4 hours, and then it was left overnight to cool. The chemical composition was identified by using the XRF spectrometer according to ASTM C114-00. The complete chemical composition of produced amorphous RHA is summarized in Table 4. As shown in Table 4, RHA contains mainly silica, 
Table 4 The results of XRF test for RHA

\begin{tabular}{cc}
\hline \hline Item & Percentage by weight (\%) \\
\hline $\mathrm{SiO}_{2}$ & 82.40 \\
$\mathrm{Fe}_{2} \mathrm{O}_{3}$ & 0.26 \\
$\mathrm{Al}_{2} \mathrm{O}_{3}$ & 0.65 \\
$\mathrm{CaO}$ & 2.42 \\
$\mathrm{MgO}$ & 1.71 \\
$\mathrm{SO}_{3}$ & 0.52 \\
$\mathrm{Na}_{2} \mathrm{O}$ & 0.30 \\
$\mathrm{~K}_{2} \mathrm{O}$ & 1.63 \\
$\mathrm{TiO}_{2}$ & 0.01 \\
L.O.I & 10.09 \\
\hline
\end{tabular}

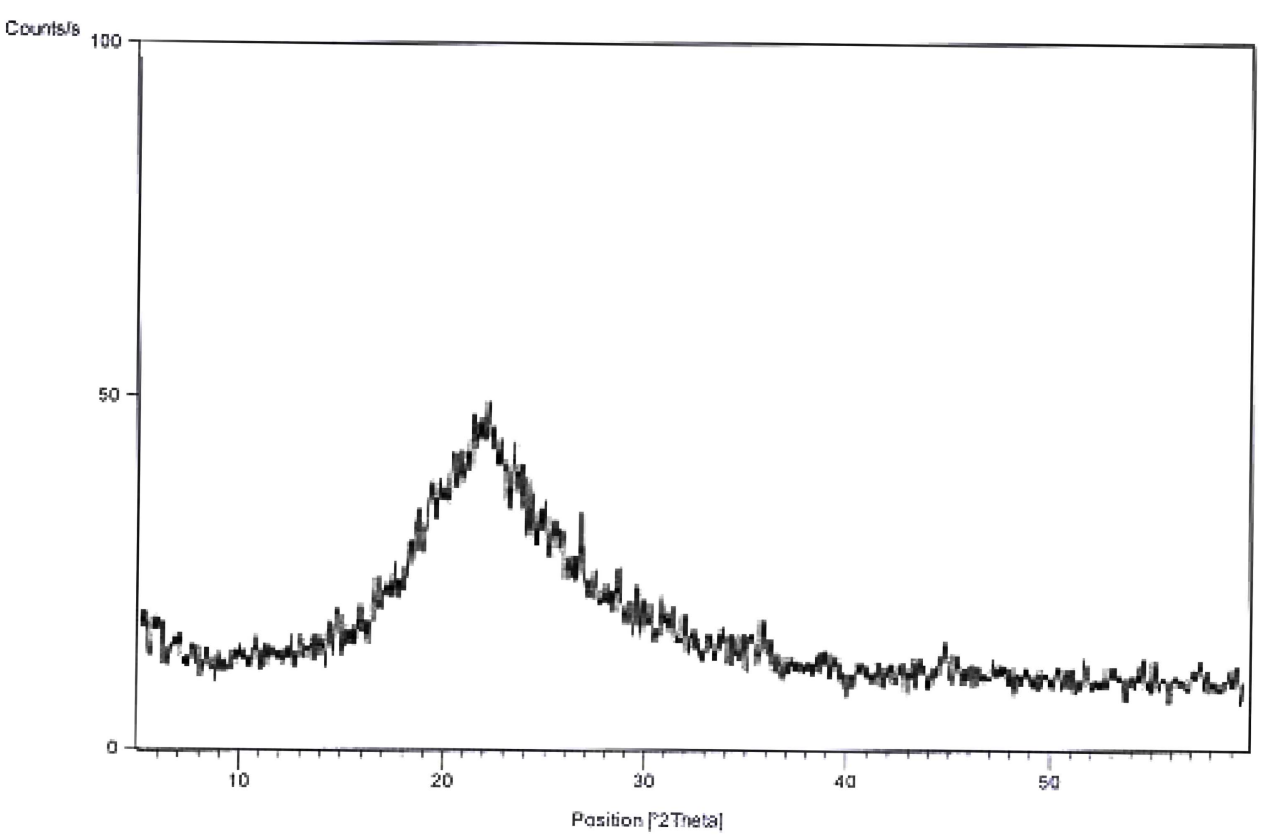

Fig. 5 XRD patterns for the RHA

which is the major chemical composition of the brick clay. RHA indicated amount of alkalies (1.93 $\%$ ) as a $\mathrm{K}_{2} \mathrm{O}$ and $\mathrm{Na}_{2} \mathrm{O}$. RHA also indicated $10.09 \%$ as L.O.I. which may be due to the presence of free carbon in the RHA. These facts indicate that RHA could be an excellent substitute for brick clay. The phase composition was identified by using the XRD diffractometer, according to ASTM C114-00. The phase composition of RHA is shown in Fig. 5.

The XRD scans were recorded from $5-60^{\circ} 2 \theta$. The XRD pattern of the RHA, shown in Fig. 5, indicates that silica in the rice husk initially exists in the amorphous form, but will not remain porous and amorphous, when incinerated for a prolonged period at a temperature above $700^{\circ} \mathrm{C}$ (Farooque et al. 2009). These results indicate that the RHA presents, in its composition, amorphous 
silica that is similar to that commonly occurring in brick clays. The RHA was produced in the form of coarse ashes with large particle size, which require pulverizing before using in brick manufacturing, as in case of clay and dried sludge. The pulverizing of the RHA was carried out, using a ball mill, which consists of a 30 liters drum mounted on a pair of rollers and driven by an electric motor. The "balls" were made of steel and should be free to move inside the drum. The pulverizing process was sustained for several minutes, till the RHA transform completely into fine dust. After pulverizing, the produced pulverized RHA was ready to be used in brick manufacturing.

\subsection{Sample preparation}

The batching proportions of raw materials required to produce lab-scale brick with nominal dimensions of $(5 \times 5 \times 2)$ cubic centimeter are shown in Table 5. Four different series of mixing ratios were tried, which included the control brick series.

Several mixing and preparation techniques were attempted. The best sample preparation technique was adopted. Mixing of the raw materials includes two main steps, dry mixing and the blending with water. The raw materials were mixed mechanically, to ensure homogeneity of the mixture. The mixed paste was then placed in an iron mold and compressed using a hydraulic piston to produce a green brick with the required nominal dimensions of $(5 \times 5 \times 2)$ cubic centimeter. This process is an analog for the extrusion machine, which is used in modern brick factories. The drying of green molded bricks is then carried out in two steps. The first step is the enclosing and stacking of the green bricks in an air-tight box for not less than six days, till complete volumetric shrinkage takes place without cracking. The green bricks are then subjected to direct air drying and sunlight for another six days. Each of the four brick series, which mentioned previously in Table 5, were then fired at four different firing temperatures, $900,1000,1100$, and $1200^{\circ} \mathrm{C}$ giving a 16 different brick types. The produced bricks were tested for mechanical properties.

\subsection{Evaluation of brick}

Water absorption, efflorescence, and compressive strength were evaluated for assessing the mechanical and physical properties of the manufactured bricks. The test methods were carried out

Table 5 The batching proportions of ingredients

\begin{tabular}{cccccc}
\hline \hline Brick Series Designation & \multicolumn{5}{c}{ Proportions by Weight (\%) } \\
\cline { 2 - 6 } & Sludge & SF & RHA & Clay & Water (additional) \\
\hline Control Brick & 0 & 0 & 0 & 100 & 30 \\
Series-A & 25 & 50 & 25 & 0 & 40 \\
Series-B & 50 & 25 & 25 & 0 & 50 \\
Series-C & 25 & 25 & 50 & 0 & 50 \\
\hline
\end{tabular}

Table 6 E.S.S. $1524 / 1993$ brick specifications

\begin{tabular}{cccc}
\hline \hline Purpose & Compressive strength $\left(\mathrm{kg} / \mathrm{cm}^{2}\right)$ & Water absorption $(\%)$ & Efflorescence \\
\hline Load bearing & 35 & 27 & Slight \\
Non load bearing & 15 & 30 & Slight \\
\hline
\end{tabular}


according to E.S.S. No. 48,619/ 2003 and the results of these properties are evaluated according to E.S.S. No. 1524/1993, as shown in Table 6.

\section{Results and discussion}

All tests were performed on $(5 \times 5 \times 2)$ cubic centimeter prisms. The result of any test was the average of three prisms, to ensure the reliability of the results. The test results of the 16 different types of brick, which include the control clay brick, are listed below. The results were also compared to two of the commercial clay-brick types available in the Egyptian market, taking into consideration that all physical properties are comparable. One of them was a solid clay-brick type and was referred to as "Commercial Brick Sample (1)" while the second was perforated wire-cut clay-brick type and was referred to as "Commercial Brick Sample (2)".

The durability of the brick is largely dependent upon their water absorption. The water absorption test results are shown in Fig. 6. The water absorption test results of control clay brick ranged between 9.94 and $11.18 \%$. On the other hand, the water absorption test results of sludge-SF-RHA brick ranged between 16.24 and $52.11 \%$. There were six sludge-SF-RHA brick types that achieved water absorption less than $27 \%$, which complies with the requirements of the E.S.S. 1524/1993 for the load bearing walls. These brick types were of series (A), (B), and (C) and fired at 1100 and $1200^{\circ} \mathrm{C}$. Also, there was one brick type that exhibited water absorption less than $30 \%$, which was of series (A) and fired at $1000^{\circ} \mathrm{C}$. This brick type met the requirements of the E.S.S. 1524/1993 for the non-load bearing walls. The effect of firing temperatures on water absorption was attributed to the fact that increasing firing temperature ensured the completion of the crystallization process and closed the open pores in the sinter. In general, brick series (C), which contained the highest RHA content, exhibited higher water absorption for all firing temperatures. This may be attributed to the flabby nature of the RHA particles, which severely increased the open pores in the sinter. Also the brick series (A), which containd the highest SF content, exhibited lower water absorption for all firing temperatures. This may be attributed to the very fine particle size of SF. Compared to the control clay brick types, all of the sludge-SF-RHA brick types exhibited higher water absorption than that of the $100 \%$ clay brick type for the same firing temperatures. Compared to the commercial brick types, there were only four of the sludge-SF-RHA brick types that achieved lower water absorption than Commercial Brick Sample (1), which attained $21.19 \%$ water absorption. These three types were of series (A) and fired at $1100^{\circ} \mathrm{C}$ and of series (A), (B), and (C) and fired at $1200^{\circ} \mathrm{C}$. While all of the research sludge-SF-RHA brick types exhibited higher water absorption than Commercial Brick Sample (2), which attained 10.77\% water absorption. These results indicate that there were seven sludge-SF-RHA brick types achieved acceptable water absorption for different uses.

Brickwork sometimes develops an efflorescence of white salts brought to the surface by water and deposited by evaporation. These salts may have an external origin, like the water in soil in contact with the brickwork, or may derive from the mortar. However, the salts frequently originate in the bricks themselves. Visible efflorescence can be formed from very small amounts of salts. Efflorescence may be disfiguring but it is often harmless and disappears after a few seasons. However, efflorescent salts may contain a high proportion of sulfates and may cause sulfate attack on the cement mortar joints. The efflorescence was of "Nil" class for all of the control clay brick and sludge-SF-RHA brick types, which complies with the requirements of the E.S.S. 1524/1993. These results could be considered as an indicator for the very low values of soluble salts content of 


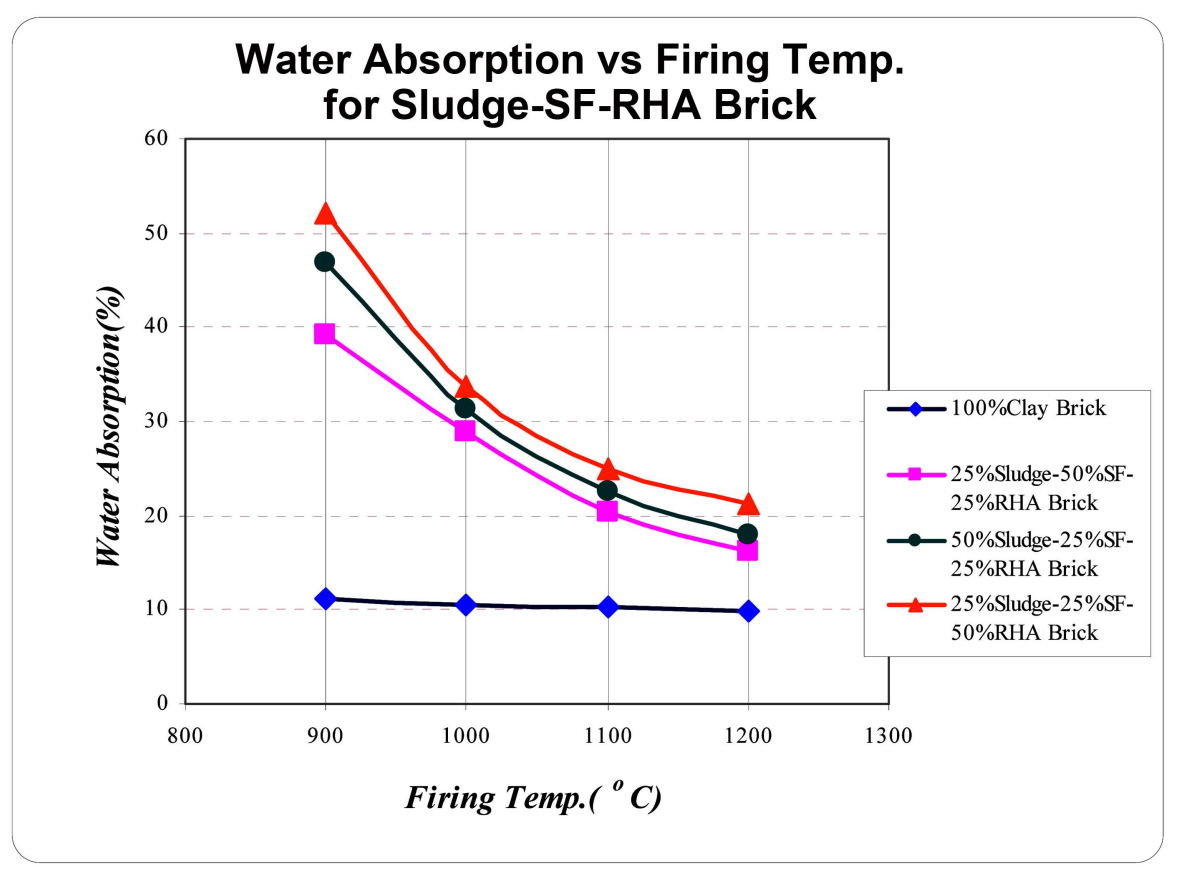

Fig. 6 Results of water absorption test with respect to proportions of each component and firing temperatures

the brick. Also, the commercial brick types exhibited no efflorescence.

Compressive strength determines the potential for application of the bricks. Compressive strength is usually affected by the porosity, pore size, and type of crystallization. It is usually defined as the failure stress measured normal to the bed face of the brick. The compressive strength test results are shown in Fig. 7. The compressive strength test results of control clay brick ranged between 58.09 and $69.44 \mathrm{~kg} / \mathrm{cm}^{2}$. On the other hand, the compressive strength test results of sludge-SF-RHA brick ranged between 51.35 and $82.83 \mathrm{~kg} / \mathrm{cm}^{2}$, which comply with the requirements of the E.S.S. 1524/ 1993 for the load bearing walls. The effect of firing temperatures on compressive strength may be attributed to the fact that increasing firing temperature ensured the completion of the crystallization process, closed the open pores in the sinter, and, consequently, increased compressive strength of the crystalline aluminosilicate brick. Compared to the control clay brick, there were only three of the sludge-SF-RHA brick types that exhibited lower compressive strength than that of the $100 \%$ clay brick types for the same firing temperatures. These types were of series (C) and fired at 900 , 1000 , and $1100^{\circ} \mathrm{C}$. Compared to the commercial brick types, all of the sludge-SF brick types achieved higher compressive strength than Commercial Brick Sample (1), which attained $27.51 \mathrm{~kg} /$ $\mathrm{cm}^{2}$ compressive strength. While only one type of the research sludge-SF-RHA brick types achieved higher compressive strength than Commercial Brick Sample (2), which attained $79.57 \mathrm{~kg} / \mathrm{cm}^{2}$ compressive strength. This type was of series (A) and fired at $1200^{\circ} \mathrm{C}$. Generally, the compressive strength of all the research sludge-SF-RHA brick types was competitor to that of the control clay brick types and the commercial clay-brick types that available in the Egyptian market. It should be noted that, with respect to mechanical properties, the use of $(5 \times 5 \times 2)$ cubic centimeter prisms should over estimate the obtained strength of the research brick types. So, by using $(5 \times 5 \times 2)$ cubic 


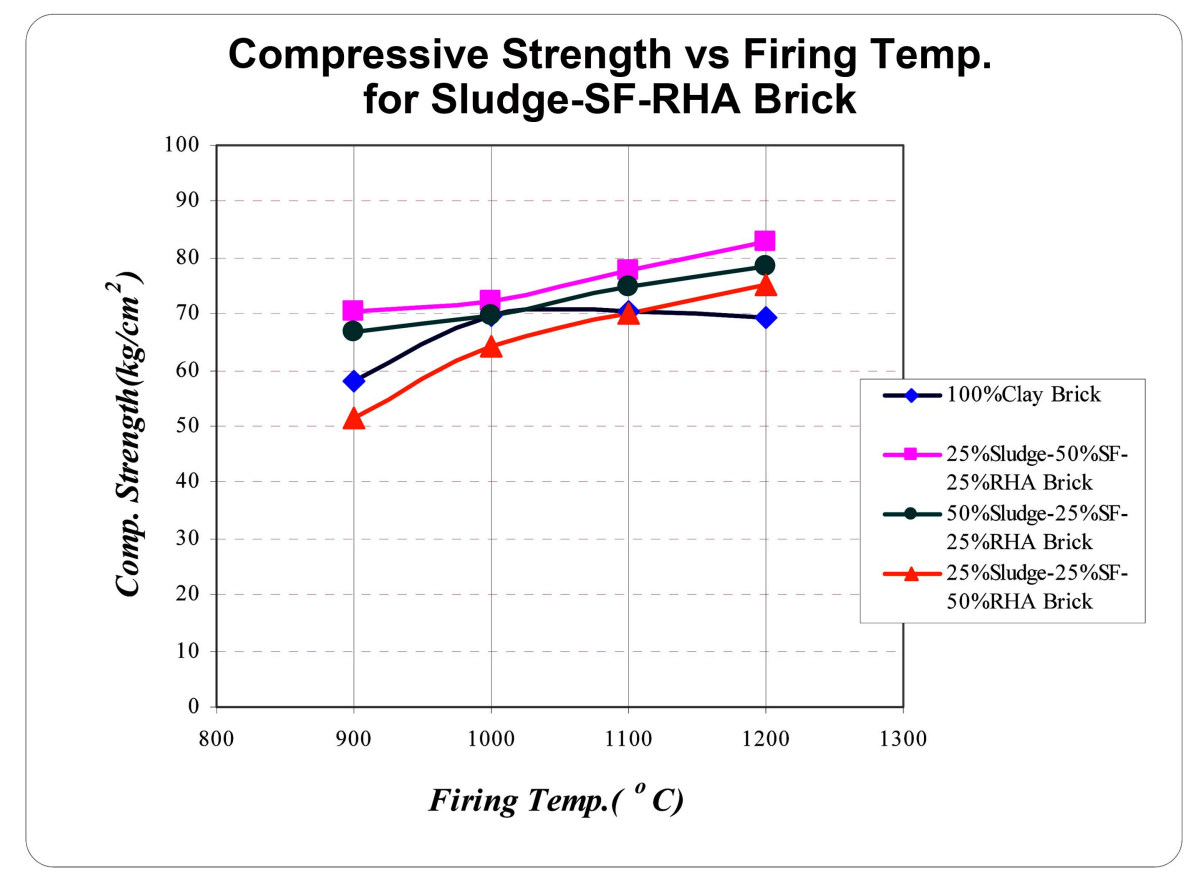

Fig. 7 Results of compressive strength test with respect to proportions of each component and firing temperatures

centimeter prisms, the compressive strength will be magnified compared to similar sample of $(25 \times 12.5 \times 6.5)$ cubic centimeter size (Neville 1989).

\section{Conclusions}

The following conclusions had been reached based on the experimental program executed in this research, and limited on both the tested materials and the testing procedures employed:

1. WTP sludge can be successfully used in brick manufacture incorporated with agricultural and industrial waste materials, which contain high silica content, such as RHA and SF. The results are limited to the study conditions such as mixing proportions, firing temperatures, and manufacturing methods used in this study.

2. The chemical composition of water treatment plant sludge was extremely close to brick clay but higher sintering temperatures are required for sludge due to its lower silica and higher alumina contents.

3. The maximum percentage of WTP sludge, which can be used in the mixture, should be determined by the practiced firing temperatures.

4. Generally, the test results in the aspect of water absorption, efflorescence, and compressive strength showed that most of the research brick types were superior to both the research control clay brick types and commercial clay brick types available in the Egyptian market.

5. A mixture consists of $50 \%$ of WTP sludge, $25 \%$ of SF, and $25 \%$ of RHA was the optimum 
materials proportions to produce brick from water treatment plant sludge incorporated with SF and RHA; by operating at the temperatures commonly practiced in the brick factories and based on the experimental scheme such as tested materials and testing procedures employed in this research.

\section{Acknowledgements}

The authors thank the staff of Giza Water Treatment Plant, for their great help in accomplishing this work. Thanks are also due to the staff of Laboratory of Testing and Properties of Materials, Faculty of Engineering at Shoubra, Benha University, Cairo, for providing the proper facilities to accomplish this work.

\section{References}

ASTM C114-00 (2005), Standard Test Methods for Chemical Analysis of Hydraulic Cement.

Belonio, A.T. (2005), Rice Husk Gas Stove Handbook, Central Philippine University, Philippines.

Chiang, K.Y., Chou, P.H., Hua, C.R., Chien, K.L. and Cheeseman, C. (2009), "Lightweight bricks manufactured from water treatment sludge and rice husks", J. Hazard. Mater., 171(1-3), 76-82.

Crisp, P.T. and Chowdhury, A.H. (2001), "Design of a low-cost purification system for the removal of arsenic from tubewell water in Bangladesh and India", BUET-UNU International Workshop on Technologies for Arsenic Removal from Drinking Water, Bangladesh, May.

Egyptian Standard Specifications E.S.S. 1524/1993 (1993), The Standard Specifications for Clay Bricks.

Egyptian Standard Specifications E.S.S. 48,619/2003 (2003), The Standard Methods for Testing of Building Bricks, Part 1: Standard Methods for Physical Tests of Building Bricks.

Farooque, K.N., Zaman, M., Halim, E., Islam, S., Hossain, M., Mollah, Y.A. and Mahmood, A.J. (2009), "Characterization and utilization of Rice Husk Ash (RHA) from rice mill of Bangladesh", Bangladesh J. Sci. Ind. Res., 44(2), 157-162.

Feenstra, L., Wolde, J.G.T. and Eenstroom, C.M. (1997), "Reusing water treatment plant sludge as secondary raw material in brick manufacturing", Proceedings of the International Conference on the Environment and Technical Implications of Construction with Alternative Materials, Houthem, June.

Godbold, P., Lewin, K., Graham, A. and Barker, P. (2003), "The potential reuse of water utility products as secondary commercial materials", WRc Report No. UC 6081.

Hassanain, A.M. (2008), Brick Manufacturing from Water Treatment Plant Sludge, M.Sc. Thesis, Benha University, Benha, Egypt.

Hegazy, B.E. (2007), "Brick making from water treatment plant sludge", J. Eng. Appl. Sci., 54(6), 599-616.

Holland, T.C. (2005), Silica Fume User's Manual, Silica Fume Association, Free Highway Association, FHWAIF-05-016, USA.

Huang, C., Pan, J.R. and Liu, Y. (2005), "Mixing water treatment residual with excavation waste soil in brick and artificial aggregate making", J. Environ. Eng., 131(2), 272-277.

Huang, C., Pan, J.R., Sun, K.D. and Liaw, C.T. (2001), "Reuse of water treatment plant sludge and dam sediment in brick-making", Water Sci. Technol., 44(10), 273-277.

Jauberthie, R., Rendell, F., Tamba, S. and Cisse, I. (2000), "Origin of the pozzolanic effect of rice husks", Constr. Build. Mater., 14(8), 419-423.

Kadri, E.H. and Duval, R. (2009), "Hydration heat kinetics of concrete with silica fume", Constr. Build. Mater, 23(11), 3388-3392.

Lai, J.Y. and Liu, J.C. (2004), "Co-conditioning and dewatering of alum sludge and waste activated sludge", Water Sci. Technol., 50(9), 41-48.

Lin, C.F., Wu, C.H. and Ho, H.M. (2006), "Recovery of municipal waste incineration bottom ash and water treatment sludge to water permeable pavement materials", Waste Manage., 26(9), 970-978. 
Mahvi, A.H., Maleki, A. and Eslami, A. (2004), "Potential of rice husk and rice husk ash for phenol removal in aqueous systems", Am. J. Appl. Sci., 1(4), 321-326.

Nagar, R.M.S. (2008), "Effectiveness of Al- and Fe- based drinking water treatment residuals in remediating

soil arsenic: mechanisms and implication", Ph.D. Thesis, The Graduate Faculty, University of Texas at San Antonio, USA.

Neville, A.M. (1989), Properties of Concrete, 3rd Edition, Pitman Publshing, London.

Prakhar, P.E. and Arup, K.S. (1998), Donnan Membrane Process: Principles \& Application in Coagulant Recovery from Water Treatment Plant Residuals, Lehigh University, Bethlehem, PA.

Prasad, C.S., Maiti, K.N. and Venugopal, R. (2003), "Effect of substitution of quartz by rice husk ash and silica fume on the properties of whiteware compositions", Ceram. Int., 29(8), 907-914.

Rahman, M.A. (1987), "Properties of clay-sand-rice husk ash mixed bricks", Int. J. Cem. Comp. Lightweight Concrete, 9(2), 105-108.

Rahman, M.A. (1988), "Effect of Rice Husk Ash on the Properties of Bricks Made from Fired Lateritic SoilClay Mix”, Mater. Struct., 21(3), 222-227.

Ramadan, M.O., Fouad, H.A. and Hassanain, A.M. (2008), "Reuse of water treatment plant sludge in brick manufacturing", J. Appl. Sci. Res., 4(10), 1223-1229.

Toya, T., Nakamura, A., Kameshima, Y., Nakajima, A. and Okada, A. (2007), "Glass-ceramics prepared from sludge generated by a water purification plant”, Ceram. Int., 33(4), 573-577. 